\title{
Research on the Accounting Management Information System of China Retail Chain Hotels
}

\author{
Baozhen $\mathrm{Han}^{1, \mathrm{a}}$, Chuanbao $\mathrm{Yu}^{1, \mathrm{~b}}$ and Haiyan Sun ${ }^{1, \mathrm{c}}$ \\ ${ }^{1}$ Qingdao Vocational and Technical College of Hotel Management, Qingdao, Shandong, China \\ asylviahbz@126.com, b44373168@qq.com, 'shysf1799@163.com
}

Keywords: Hotel Chain, Financial Management, Retail Chains

\begin{abstract}
The hotel chain mode of operation mainly concludes directly, joining and cooperation types, and directly type hotel chain of financial management has its own characteristics. In order to adapt to the characteristics of the hotel, ensure normal operation of retail type hotel chain, it is very important to for the financial management to pay special attention to four aspects. First is doing systematic to improve the rules and regulations. Second is Strengthen the daily supervision to ensure behavior. Third is using the management system to improve the efficiency of management strengthening training to improve the overall quality. Forth is strengthening training to improve the overall quality.
\end{abstract}

\section{Introduction}

Generalized human resources refers to people with normal intelligence, is the ability to work in population within a certain area have the sum of [1]. Even if the concept of human resources information management in today has been widely used, but there doesn't have a clear definition. [2] Human resource management emerged in the late $1970 \mathrm{~s}$, as a response to the increasingly fierce competition and the increasing liquidity of a rise in the market management, its purpose is to coordinate the relationship between the employees, to ensure the staff's efforts to focus on for best performance in the organization [3].In the $1990 \mathrm{~s}$ European human resource management is the core of the academic research field, this stage a large number of studies have focused on European background on the problem of the personnel management of cross-cultural [4].

Chain hotel as a kind of management mode of hotel development has become increasingly common; it has the boost to the coordination of hotels, in turn, has an important significance to improve the hotel's profitability, but also puts forward new requirements and challenges on the financial management of hotel chain. The financial management of hotel chain should choose different management patterns according to different ways. But the focus is to build efficient financial management system, to establish the core status of the headquarters of the financial, to give full play to the headquarters of the financial management function.

According to the headquarters and the control relationship of retail enterprises, chain operation can be divided into retail chain, franchise chain and voluntary chain, etc. Retail type hotel chain according to the mutual relationship between the capital, also can be divided into two different ways: retail chain pattern of wholly owned and holding type retail chain mode. The essence of wholly owned retail chain hotel is the relationship between head office and branches. All funding of branches stores is from head office, all transactions of branches stores shall be in the charge of the head office, including the branch manager is appointed by head office, branches are only responsible for the daily operation and management. Holding type retail chain hotel is the head office to branch into certain funds, holding in store to store according to the joint-stock enterprises. Retail chain has certain universality. Franchise chain type joining chain, also known as a way of chain is through the contract implementation, head office has no ownership of branch, only the management of unified management, often accompany some franchises, and get some interests from authorized. Voluntary chain hotels take some common interest as the bond, on the basis of the contract to carry out the mutual support and assistance, mutual relationship between relatively loose and independent each other between the shop and the shop. Because of the directly and franchising relationship between 
head office and branch in three models, it can produce management relationship of two kinds of chain but voluntary chain does not have set up this relationship. Directly type management model in hotel chain do set examples so the analysis of the financial management, financial management of all kinds of chain business hotel is of great significance.

\section{Analysis on the financial management of retail type hotel chain}

Financial Management of Wholly Owned Retail Chain Hotel: Because of the strict head office and branch relationship of wholly owned hotels, all the affairs of the branch, is responsible by the head office. Including logistics, management system, human resource, compensation, financial accounting, and even the hotel logo, staff dress should be unified. Finance of branches should be in charge of the head offices which mainly embody in the following aspects: The first is financial personnel equipped with. Financial personnel shall be approved by the head office on the operating status of the branch. The second is the unity of the financial system. Each branch is set by the head office unified financial system, and according to the standard operation. The third is financial personnel assessment. Each branch of the financial personnel should be determined by the head office is responsible for the examination. Fourth are the financial personnel trainings. Financial personnel should be determined by the head office is responsible for the centralized training, in order to fully realize the unity of financial control system. Fifth is the concentration of the financial system. Each branch of the financial system must be collected within a total system, the head office of the treasurer can view real-time each branch of the financial conditions and operating conditions.

Financial Management Holding Company Straight Camp Hotel Chain: The hotel chain financial management should be carried out in accordance with the mechanism of joint-stock enterprises. For holding type hotel chain, its financial can draw lessons from wholly owned hotel, to control the hotel's day-to-day finances more strict, in the same way, taking main responsibility for problems arising from the financial activities, also should be in accordance with the principle of shares. And paying attention to other shareholders to give consideration to opinions that other stockholders give on financial management aspect and the decision is on controlling. Financial personnel should be sent by mainly controlling party.

The Characteristic of the Financial Management in the Retail Chains: For retail financial management of hotel chain, there are the features of "three little three much ", unified, less concentrated more freedom, more dispersed less struggle more belong to less. From financial standards more dispersed less unity. Due to the needs of centralized management, retail type hotel chain, principle of the unity of the operation should be determined according to the head office from the financial system to the summary to unify the accounting information and financial policy and tax to unify, analysis, budget, caliber to unify, by head office for stores operating the dynamic control of financial personnel for deployment will faithfully perform head office. Head office of the relevant policy relatively is easy to implement into practice, is advantageous to the head office of branch execution of assessment index and the implementation of unified procurement attended to, etc., branch of the financial operation has reduced the risk dispersion and run. Looking from the financial management it focuses more on freedom, realize the centralized management of funds, the formation of uniform cash flow, unified deployment, unified financial management, unified investment, reduce the risk of capital precipitation and, increasing the utilization of funds. After the head office of branch operation fully centralized will bring another problem, namely the branch managers due to the shrinking of degrees of freedom, the financial control are constrained by the head office, business enthusiasm will be affected by certain influence, thus affect the operational efficiency [5].

After the head office of branch operation fully centralized will bring another problem, namely the branch managers due to the shrinking of degrees of freedom, the financial control are constrained by the head office, business enthusiasm will be affected by certain influence, thus affect the operational efficiency. Look from the financial personnel it will be more entanglement and less affiliation. Due to financial head office manager, branch financial personnel will produce a tangle, on the headquarters financial dependence, when they have a problem, they just want to give it up to head office, instead of thinking about solutions themselves, or shirking responsibility, the result is not conducive to timely 
solve the problem of branch daily operations; Branch financial as to the need to communicate with head office, active response to changes in market environment consciousness is weak, lacking the ability to deal with, will not well serve as a store operator's assistant, Branch financial personnel feedback to the head office of the problem may be due to information asymmetry, financial headquarters from head office to make miscalculation or outlet is not accurate when financial personnel to communicate; Owing to the branch of financial personnel appointed by head office and head office inspection management, so easy to cause the gap between financial personnel and branch managers, financial personnel will think the stores don't need to cooperate with other departments, also don't have to be involved in too many business, only responsible for the headquarters, branch managers will think financial personnel is headquarters of the people, they just to do a good job of accounting, other business activities has nothing to do with them. The resulting participation strong financial personnel is difficult to play a positive role, easy to form the harmonious mood, cause financial personnel isolated situation, work harder. Caused by objective possibility of a separate existence, branch managers for branch financial personnel in the inspection focus only on task, rather than accuracy, sometimes mixed emotions, so head office to branches of financial personnel assessment can only reflect from direct business dealings, the other is hard to learn.

About how to solve the "three low" problem, this is an important problem in financial management in directly type hotel chain, but also a test for retail chain hotel the whole set of accounting systems, management and daily operation.

\section{The key point of financial management of retail chain hotel}

The financial management of hotel chain is more complicated than a single hotel. In addition to the above characteristics, objectively, there are some reasons. First is hotel geographical dispersion. This is the inevitable phenomenon of the hotel chain. Branches may be distributed everywhere, there is distance space. Second is financial personnel dispersion. Because financial personnel work with the hotel, so geographically dispersed, bound to lead to financial personnel dispersion although can through the mechanism of financial personnel together, but problems exist objectively. Third is complex management structure. Hotel chain of financial management is a multi-level problems, there are at least two levels of management between head office and branches, if they are holding type retail chain, not only has the internal task hierarchy and external exchanges and consultation. Fourth, there is a certain risk. For head office, because of the financial personnel the actual work in the hotel, head office does not understand the personnel situation in time, if there is a bad cooperation between financial personnel and the manager, then there is a certain financial risks are inevitable. In order to deal with hotel chains have problem objectively, and at the same time in order to guarantee the normal healthy running of the hotel, retail type hotel chain of financial management should do well in the following priority:

Do Systematic to Improve the Rules and Regulations: Rules and regulations are the basic principles that the hotel chain should obey. Setting up a corresponding system can make the financial work standardization, standardization, management of the branch is to ensure that head office an essential prerequisite for the smooth implementation, ensure the normal operation of the hotel, especially to ensure the safe operation of the financial foundation and guarantee, so as to realize the operation target of headquarters.

Strengthen the Daily Supervision to Ensure Behavior: For hotel operators, how to protect the rights and interests of all parties, as well as power, is also responsibility. In order to prevent a variety of possible happens, avoid harm the interests of all parties, to strengthen the supervision of each store daily financial work. The purpose of regulation is to ensure that the specification and the implementation of the system. Such regulation can be managed with regular or irregular spot checks, on-site inspection, etc. It's necessary to strengthen day audit, internal audit and carry out regular and irregular audit. Strengthen the audit and management of its budget, control branch operation cost, and improve the ability of the hotel and the effect. To analysis of the financial condition of each branch timely, daily operation of the basic characterization in branches, find problems in time, solve the problem in a timely manner, to correct the problem timely, ensure the healthy development of the 
hotel. Can also take the branch system of financial personnel job rotation, can prevent the occurrence of bad behavior, and can also be used for financial training backbone.

Use the Management System to Improve the Efficiency of Management: Geographical spread objectively can bring difficulties to the practical work so for financial management of the hotel chain should make full use of modern science and technology through the Internet and other means to shorten the hotel between the actual space distances to improve the efficiency of management. Through the establishment of a management accounting as the core material resource management involves (logistics), human resource management (people), financial resources management (goods flow), information resources management (information) can provide from the aspects such as trans-regional, cross-sectorial, even across company integrating real-time information management system, improve the management efficiency of the hotel chain.

Strengthen Training to Improve the Overall Quality: Financial personnel training lies in the ability of the business in the first place. Financial personnel scattered the shop to do the financial unification to strengthen unity of training to ensure that the unity of the financial system and financial chain hotel standard. First of all make the financial personnel able to work, dare to supervise, responsible at work good at suggesting on the premise of adhering to the principle of headquarters. In order to effectively prevent the adverse phenomenon, and also to strengthen the education of legal system education, financial policy, make financial personnel observe the law not illegal. Once again, we must strengthen financial personnel's professional integrity education to prevent financial personnel harm the healthy development of the hotel through the false information violations of the right holder interests. Finally, it's necessary to strengthen the communication ability training financial personnel.

\section{Conclusions}

The case study results show that different chain operation modes have different characters. And the financial management of financial management of chain hotels should be different .Four important measures should be taken. First is doing systematic to improve the rules and regulations. Second is Strengthen the daily supervision to ensure behavior. Third is using the management system to improve the efficiency of management strengthening training to improve the overall quality. Forth is strengthening training to improve the overall quality. As the measures achieved, the financial management of chain hotels will be more extensive.

\section{References}

[1] li-shan xie. Tourism enterprise human resources management [M]. Beijing: tourism education press, 2008.

[2] Li,Z. ,Roesler,D. ,Meszlery,K. Discovering development of personnel qualification requirements by web mining:A case study[J].International Journal of Internet and Enterprise Management, 2004,(2):191 205.

[3] Susan,M. Human resource management in smaller firms:A contradiction in terms? [ $\mathrm{J}$ ] .Human Resource Management Review,2006,(16):467 477.

[4] Paul,S., Jeanm, H. European human resource management in Transition [J] .European Management Journal,1995,(13):234 235.

[5] Chen Xianxiu. The research on chain operation enterprises accounting issues (J). Contemporary economic, 2013,(16) 